\section{FRI0230 CLINICAL PRESENTATION OF 475 PATIENTS WITH PRIMARY SJÖGREN'S SYNDROME WHO WHERE SEEN BY THE RHEUMATOLOGISTS}

C Diaz, C Geli, C Diaz-Torne, H Corominas, M Moreno, A Rodriguez, JM Llobet, G Vazquez. Rheumatology, Hospital de La Santa Creu I Sant Pau, Barcelona, Spain

\subsection{6/annrheumdis-2001.323}

\section{Background}

Objectives Study the clinical presentation of primary Sjögren's syndrome (pSS) patients in a rheumatology unit.

Methods 475 patients with pSS have been studied. European criteria was used for the diagnostic. Patients with primary biliary cirrhosis and hepatitis $\mathrm{C}$ were excluded. Demografic, clinical and laboratory data were taken following the protocol of the unit. Minor salivary biopsy was carried out on $90 \%$ of the patients.

Results $94.5 \%$ were women. Age was $63 \pm 12$. Years of evolution were $10 \pm 13$. More prevalent extraglandular manifestations were: Carpal tunnel's syndrome (CTS), 40\%; fibromialgy, $36 \%$; intermitent non inflammatory arthritis, 36\%; inflammatory osteoarthritis, $10 \%$; thyroid's disfunction, $25.4 \%$; photosensibility, 20\%; peripheric neurologic manifestations without CTS, $5 \%$; central neurologic manifestations, 5\%; haematological manifestations, 8 ; renal manifestations, $5 \%$; vasculitis, $13 \%$.

Rheumatoid factor (RF) was positive in $50 \%$ of the patients, ANA in $70 \%$, antithyroidal antibodies in $27 \%$, SS-A/Ro in $23 \%$ and $\mathrm{SS}-\mathrm{B} / \mathrm{La}$ in $11 \%$.

$37 \%$ of them come because of rheumatic manifestations, (14\% fibromialgy, 14\% arthritis, 5\% inflammatory osteoarthritis, $4 \%$ Raynaud's phenomenom, another 5\% are athralgia and low back pain.) $30.5 \%$ come because of oral or ocular dryness and parotidomegalia. Other reasons for consultatioon were: autoinmmune cytopenia (5\%), thyroidal disfunctions (3\%), vasculitis (2\%), and RF or ANA (2\%).

Conclusion The most common reason for consultation were rheumatic manifestations. The second reason was the oral and ocular dryness. Analitical alterations (Cytopenias, RF, ANA) can be other reasons for consultation.

\section{FRI0231 ASSOCIATION OF SYSTEMIC SCLEROSIS WITH PULMONARY SARCOIDOSIS IN TWO CASES}

G Szucs, E Szolnoki, M Alexa, G Szegedi. Third Department of Medicine, University of Debrecen, Debrecen, Hungary

\subsection{6/annrheumdis-2001.324}

\section{Background}

Objectives

Methods A 42-year-old man has been followed up due to mediastinal lymphadeopathy and pleural effusion parallel with Raynaud syndrome, sclerodactylia and bibasal pulmonary fibrosis. $\mathrm{He}$ was diagnosed as having systemic sclerosis by the clinical symptoms and skin biopsy and sarcoidosis which was confirmed by the biopsy of mediastinal lymph nodes. A 24-year-old woman has been followed up due to sarcoidosis proved by the biopsy of mediastinal lymph nodes, too) for 3 years before the development of the clinical symptoms of systemic sclerosis.

Results In both patients sarcoidosis were successfully treated with corticosteroids (in the second case corticosteroid treatment was completed with cyclophosphamid becasue of fibrotising alveolitis). We analysed the clinical symptoms, organ manifestation, prognosis in both cases together with the examination of cytokine profile (interferon-g, IL-1, IL-2, IL-4, IL-6, TNF-a) of CD4 positive lymphocytes from periferal blood.

Conclusion Our results showed Th1 dominancy in both cases, which may play an important role in the coexistence of sarcoidosis and systemic sclerosis.

\section{OP0065 ABNORMALITIES IN THE PKC SIGNALLING SYSTEM DOWNSTREAM TO MUSCARINIC RECEPTORS IN AN EXPERIMENTAL MODEL FOR SJÖGREN'S SYNDROME (SS)}

YT Konttinen, EK Tensing, M Hukkanen, HS Fox, J Ma, J Tornwall. Department of Oral Medicine, Surgical Hospital, Helsinki, Finland

\subsection{6/annrheumdis-2001.325}

Background Postganglionic parasympathetic nerve fibers ${ }^{1}$ release acetylcholine, which binds to acinar cell muscarinic receptors. Short-term stimulation leads to activation, but long-term stimulation leads to a negative feedback in form of proteolytic degradation. Salivary glands acinar cells in SS patients lack PKC beta II and are low in PKC alpha isoform ${ }^{2}$ as if they had been consumed/proteolytically degraded.

Objectives Our aim was to study, if also NOD mice have PKC involvement, which isoforms are involved and if this involvement is of the early activation type or like is seen as a result of a long-term, autoantibody-mediated stimulation in human disease. Methods Conventinal (alpha, beta, gamma), unusual (delta, epsilon, theta) and atypical (lambda, iota) PKC isoforms were studied using immunohistochemical staining and Western blotting.

Results Control BALB/c mice had PKC alpha and beta like their human counterparts. They require calcium, DAG and phosphatidylserine for their activation. In contrast, NOD mice with sialadenitis had a strong expression of PKC alpha and beta. Transgenic NOD x IFN-gamma mice had an early involvement, but similar pattern to that of NOD mice. Acinar cells in NOD scid mice did not express any of the PKC isoforms studied.

Conclusion Findings suggest that the calcium-dependent conventional PKC isoforms are involved also in NOD mice. In contrast to the human disease, mice with a short life span display upregulation and do not reach the stage with proteolytic degradation/ loss of PKC. Interestingly, the altered PKC status modulates the susceptibility of cells to apoptosis.

\section{REFERENCES}

1 Konttinen YT, Hukkanen M, Kemppinen P, et al. Arthritis Rheum. 1992;35:81520

2 Törnwall J, Konttinen YT, Tuominen RK, Törnwall M. Lancet 1997;349:1814-15

\section{OP0066 EFFECTS OF TNF BLOCKADE WITH INFLIXIMAB IN PATIENTS WITH PRIMARY SJÖGREN'S SYNDROME: AN OPEN PILOT STUDY}

${ }^{1} \mathrm{SD}$ Steinfeld, ${ }^{2} \mathrm{P}$ Demols, ${ }^{1} \mathrm{~V}$ Gangji, ${ }^{1} \mathrm{~T}$ Appelboom. ${ }^{1}$ Rheumatology; ${ }^{2}$ Ophtalmology, Erasme University Hospital, Brussels, Belgium

\subsection{6/annrheumdis-2001.326}

Background Tumour necrosis factor $\alpha$ (TNF $\alpha)$ is a proinflammatory cytokine involved in the pathogenesis of Sjögren's syndrome (SS), and blockade of TNF $\alpha$ may reduce the activity of the disease. 
Objectives This study evaluated the safety and potential efficacy of infliximab, a chimeric human-mouse anti-TNF $\alpha$ monoclonal antibody, in patients with active primary SS.

Methods This was a monocentre, open-label pilot study. Sixteen patients with active primary SS (ESR $>25 \mathrm{~mm} / \mathrm{h}$ and hyperIgG) received three infusions of $3 \mathrm{mg} / \mathrm{kg}$ infliximab (at weeks 0,2 and 6). Standard clinical assessment, complete ophtalmological testing and functional evaluation.

Results All the patients completed the study. There was a statistically significant improvement in all clinical and functional parameters. They included global assessments $(p<0.01)$ for patient global assessment, patient pain, physician global assessment, erythrocyte sedimentation rate $(\mathrm{p}<0.05)$, salivary flow rate $(\mathrm{p}<0.001)$, Schirmer I test $(\mathrm{p}<0.01)$, lissamine green staining $(\mathrm{p}<0.05)$, tender joint count $(\mathrm{p}<0.01)$, fatigue score $(\mathrm{p}<0.001)$, dry eyes and dry mouth $(\mathrm{p}<0.01)$. This clinical benefit was observed at week 2 and was maintained throughout the study and the 2 months follow-up period. The treatment was well tolerated in all patients and no significant adverse events were seen. No lupus-like syndrome and no anti-dsDNA antibodies were observed.

Conclusion In patients with active primary SS, a loading dose regimen of three infusions of infliximab provided a fast and significant clinical benefit without major adverse reaction. It was possible to maintain statistically significant improvement up to 8 weeks after the third infusion.

\section{OP0067 USEFULNESS OF THE BASAL AND PILOCARPINE- STIMULATED SALIVARY FLOWS IN PRIMARY SJÖGREN'S SYNDROME}

1J Rosas, ${ }^{2} \mathrm{M}$ Ramos-Casals, ${ }^{1 \mathrm{~J}}$ Ena, ${ }^{2} \mathrm{M}$ Garcia-Carrasco, ${ }^{3} \mathrm{~J}$ Verdu, ${ }^{2} \mathrm{R}$ Cervera, ${ }^{2} \mathrm{~J}$ Font, ${ }^{3} \mathrm{O}$ Caballero, ${ }^{2} \mathrm{M}$ Ingelmo, ${ }^{4} \mathrm{E}$ Pascual. ${ }^{1}$ Rheumatology Unit, Hospital de Villajoyosa, Villajoyosa; ${ }^{2}$ Systemic Autoimmune Diseases Unit, Hospital Clinic, Barcelona; ${ }^{3}$ Medicina Nuclear, Hospital General Universitario, Alicante, Spain; ${ }^{4}$ Rheumatology Unit

10.1136/annrheumdis-2001.327

\section{Background}

Objectives To examine salivary function in patients with primary Sjögren's syndrome (SS) by assessing unstimulated and stimulated flows using a $2 \%$ pilocarpine solution.

Methods We investigated the clinical and immunological characteristics of 60 consecutive patients with primary SS. All patients fulfilled four or more of the preliminary diagnostic European criteria for SS. We measured unstimulated (basal) salivary flows (BSF) in all patients. In those patients with a BSF $<1.5 \mathrm{~mL}$, stimulated salivary flows (SSF) were also measured after the stimulus with an ophthalmic $2 \%$ pilocarpine solution.

Results Of the 60 patients, 55 were women and 5 men, with a mean age at the SS onset of 61 years (range 18 to 82 years). The mean BSF for SS patients was $1.40 \pm 0.17 \mathrm{~mL}$. Fifty $(83 \%)$ patients showed a BSF less than $1.5 \mathrm{~mL}$. No clinical or immunological differences were found between SS patients with BSF more or less than $1.5 \mathrm{~mL}$, although those patients with a BSF less than $1.5 \mathrm{~mL}$ showed more frequently a parotid scintigraphy class III or IV $(42 \%$ vs $0 \%, p=0.01)$. Finally, those SS patients with a pilocarpine-SSF less than $1.5 \mathrm{~mL}$ showed a higher time of SS evolution (73.3 vs 31.3 months, $\mathrm{p}=0.03$ ) and a higher prevalence of positive anti-Ro/SS-A (70\% vs $36 \%, \mathrm{p}=0.038)$, antiLa/SS-B (65\% vs 32\%, p = 0.038), parotid scintigraphy class IIIIV $(79 \%$ vs $9 \%, \mathrm{p}<0.001)$ and positive salivary gland biopsy (90\% vs $43 \%, \mathrm{p}<0.001)$.
Conclusion The study of xerostomia using basal and pilocarpinestimulated salivary flows are methods simple to perform and acceptable to patients with no special equipment. Twenty-two of the 46 patients with low BSF obtained stimulated flows over 1.5 $\mathrm{mL}$ These "responders" patients showed a lower time of evolution of sicca symptomatology, a lower frequency of positive immunological markers and milder grades of scintigraphic patterns and lymphocytic infiltrates on salivary gland biopsies.

\section{OP0068 SJÖGREN'S SYNDROME IN AN OUT-PATIENT CLINIC: CLASSIFICATION OF PATIENTS ACCORDING TO THE PRELIMINARY EUROPEAN CRITERIA AND THE PROPOSED MODIFIED EUROPEAN CRITERIA}

JG Brun, TM Madland, CB Gjesdal, LT Bertelsen. Department of Rheumatology, Haukeland University Hospital, Bergen, Norway

\subsection{6/annrheumdis-2001.328}

Background Sjögren's syndrome (SS) is defined as a chronic autoimmune condition. According to the preliminary European classification criteria ${ }^{1}$ currently in use, it is possible to diagnose SS without the evidence of autoantibodies (SSA/SSB) or specific salivary gland inflammation. In Norway, these criteria are often used as a guidance for the diagnosis in the clinical setting. In the recently proposed modification of the European criteria, ${ }^{2}$ the presence of autoantibodies or salivary gland inflammation is obligatory.

Objectives To investigate whether out-patients with a clinical diagnosis of SS satisfied formal criteria, and the proportion of patients who satisfied the proposed modified criteria and thus had indication of an autoimmune process.

Methods All out-patients with visits coded M35.0 (ICD-10) at the Rheumatology clinic from January 1, 1999 to November 1, 2000, were included in the study. Patients with secondary SS, observational patients and those misclassified were excluded.

Results Of 10720 consultations, 457 (4,3\%) were coded M35.0. Patients typically had 1-3 consultations in the period. After exclusions, there remained 203 patients who were coded correctly according to the clinical diagnosis in the journal. Of these, $116(57.1 \%)$ satisfied the current European criteria, and 83 (40.9\%) satisfied the proposed modified criteria. Thirty-four (29.3\%) of the patients satisfying current criteria lost the diagnosis of SS according to the modified criteria, while only one patient who did not previously satisfy criteria received the diagnosis.

Conclusion Sicca-symptoms and signs may have a variety of causes. In our study only $40.9 \%$ of the patients with a clinical diagnosis of SS satisfied the proposed modified European criteria and had evidence of SS as an autoimmune condition. Approximately one third of the patients meeting the preliminary European criteria for SS, lost the diagnosis according to the modified criteria.

\section{REFERENCES}

1 Vitali C, Bombardieri S, Moutsopoulos HM, et al. Preliminary criteria for the classification of Sjogren's syndrome. Results of a prospective concerted action supported by the European Community. Arthritis Rheum. 1993;36:340-7

2 Vitali C, Bombardieri S, Moutsopoulos HM, and the European Study Group for the Classification Criteria for Sjögren's syndrome. A proposal for modification of the European classification criteria for Sjögren's syndrome (Abstract). Clin Exp Rheum. 2000;18:118 